\title{
STUDY ON THE ANALYTICAL METHOD OF INORGANIC ARSENIC SPECIES IN ENVIRONMENTAL SAMPLES
}

\author{
WU, J. ${ }^{1}-$ ZHANG, S. D. ${ }^{2}-$ ZHU, X. S. ${ }^{1,3^{*}}$ \\ ${ }^{1}$ School of Chemistry \& Chemical Engineering, Yangzhou University, Yangzhou, China \\ ${ }^{2}$ Bureau of Ecology and Environment of Yangzhou, Jiangsu, China \\ ${ }^{3}$ Guangling College of Yangzhou University, Yangzhou, China \\ *Corresponding author \\ e-mail:xszhu@yzu.edu.cn,zhuxiashi@sina.com; phone: +86-514-8797-5244 \\ (Received 23 $3^{\text {rd }}$ Feb 2019; accepted $3^{\text {rd }}$ May 2019)
}

\begin{abstract}
A simple and rapid method based on ionic liquid liquid-liquid microextraction with room temperature ionic liquid 1-butyl-3-methylimidazolium hexafluorophosphate ([BMIM] $\left.\left[\mathrm{PF}_{6}\right]\right)$ coupled to electrothermal atomic absorption spectrometry (ETAAS) was developed for the speciation of arsenite $(\mathrm{As}(\mathrm{V})) /$ arsenate $(\mathrm{As}(\mathrm{III}))$ in environmental samples. In this method, $\mathrm{As}(\mathrm{V})$ can be extracted by $[\mathrm{BMIM}]\left[\mathrm{PF}_{6}\right]$ at $\mathrm{pH} 6.5$ due to the formation of a hydrophobic complex, whereas As(III) remains in the aqueous solution. The $\mathrm{As}(\mathrm{V})$ and $\mathrm{As}(\mathrm{III})$ concentration were analyzed by ETAAS respectively. Various factors including $\mathrm{pH}$, volume of [BMIM][ $\left.\mathrm{PF}_{6}\right]$, equilibrium temperature and time, effect of salt by single factor experiment design and orthogonal experimental design. Under the optimized conditions, the limits of detection $(3 \sigma)$ were $0.04 \mathrm{ng} / \mathrm{mL}$ and $0.35 \mathrm{ng} / \mathrm{mL}$ for $\mathrm{As}(\mathrm{V})$ and $\mathrm{As}(\mathrm{III})$, and its relative standard deviations was $3.5 \%$ and $2.9 \%$ respectively $(\mathrm{n}=9, \mathrm{c}=20.00 \mathrm{ng} / \mathrm{mL})$. The proposed procedure was applied without any chelating agent or dispersive agent. The method was validated against the certified reference materials (GBW08666), and successfully applied to determine $\mathrm{As}(\mathrm{V})$ and $\mathrm{As}(\mathrm{III})$ in real environmental samples.

Keywords: $A s(V), \quad A s(I I I)$, ionic liquid, liquid-liquid microextraction, 1-butyl-3-methylimidazolium hexafluorophosphate, atomic absorption spectrometry, orthogonal experiment design, single factor optimization method
\end{abstract}

\section{Introduction}

Arsenic is an abundant and high toxic element in the natural. The sources of arsenic can be divided into natural and man-made sources. The former is mainly arsenic in geological rocks, which is determined by the arsenic content in the soil, and the latter comes mainly from pesticides, fertilizers and mining smelters, such as lead arsenate and calcium arsenate, which are used to control insect pests of fruit trees or cottons; zinc methylarsonate used to control rice sheath blight, arsenic in medicament present in dentistry, used to kill nerve. Arsenic containing waste water, waste gas and waste residue were carried into the environment and raised environmental pollution, this pollution must be controlled by human beings. An important step in controlling this pollution is the determination of arsenic, and this involves the determination of arsenic speciation. Arsenic is divided into inorganic arsenic and organic arsenic, and their toxicity is very different. Inorganic arsenic and organic arsenic species have different toxicological behavior and biochemical activity. The As(III) is 10 times greater toxicity than As(V), and also seven times than methyl arsenate (MMA) and dimethyl arsenate (DMA) (Squibb et al., 1983). Many countries and regions have therefore established the maximum allowable limits of arsenic and its compounds in drinking water (United States Environmental Protection Agency, 2002; Ministry of Public Health of the People's Republic 
of China, 2007). Arsenic speciation is of more significant than total arsenic determination for evaluating their toxicity on human beings, as well as monitoring environmental pollution.

The direct determination of arsenic species at very low concentrations is always an impossible task due to the insufficient sensitivity of method, as well as the complicated matrix interferences occurring in samples. Generally, a preliminary separation and preconcentration step is often required for this reason. Numerous separation/analysis methods with primary separation steps for the speciation of $\mathrm{As}(\mathrm{V})$ and $\mathrm{As}(\mathrm{III})$ have been proposed, such as highperformance liquid chromatography and inductively coupled plasma mass spectrometry ( $\mathrm{Li}$ et al., 2017), flow injection analysis and chemiluminescence detection (FIA-CD) (Nellaiappan et al., 2018), solid phase extraction electrothermal atomic absorption spectrometry/atomic fluorescence spectrometry (SPE-ETAAS) (Tunçeli et al., 2015; Abdolmohammad-Zadeh et al., 2013; Pourghazi et al., 2015), liquid-liquid microextraction-electrothermal atomic absorption spectrometry (LLME-ETAAS) (Wang et al., 2018). LLME is one of the efficient techniques to separate and concentrate metal ions, our research team has developed this method for the determination of many metals (Wen et al., 2013, 2014; Wen and Zhu, 2014). There are many advantages for LLME, such as easy operation, fewer solvents and rapidness. However, the method involves the use of organic solvents which generally are toxic and hazardous to organisms and environment.

Ionic liquids (ILs) were deemed as new green solvents (Wen et al., 2014), they seem very promising replacements for the traditional volatile organic solvents in the sample preparation. The ionic liquid liquid-liquid microextraction (IL-LLME) has received considerable attention for its convenience and simplicity compared with traditional liquid-liquid extraction, including lower cost, higher enrichment factor, and lower consumption of toxic organic solvent (Stanisz et al., 2014). 1-butyl-3-methylimidazolium hexafluorophosphate ([BMIM] $\left.\left[\mathrm{PF}_{6}\right]\right)$-based microextration procedures were proved to be environmentally friendly and efficient for the preconcentration of heavy metal ions in biological and environmental samples (Arain et al., 2016; Sha et al., 2014). However, the application of [BMIM] $\mathrm{PF}_{6}$ ] for the speciation of $\mathrm{As}(\mathrm{V})$ and $\mathrm{As}(\mathrm{III})$ based on IL-LLME has not been explored so far.

In this work, $[\mathrm{BMIM}]\left[\mathrm{PF}_{6}\right]$ was synthesized, and used to extract/separate inorganic arsenic. As(V) was extracted by ionic liquid directly, while As(III) remains in aqueous phase at $\mathrm{pH}$ 6.5, then, a new method for the determination of arsenic by LLME-ETAAS was established. The new method is simple to operate. The proposed procedure does not need any chelating agent, and it also does not require any dispersants, reduce the harm to environment in preliminary separation/preconcentration step obviously. All parameters are optimized by single factor experiment design; furthermore, the orthogonal experiment design is used to optimize the conditions based on the above results. Under the optimized experimental conditions, the developed method was applied for the determination of $\mathrm{As}(\mathrm{V}) / \mathrm{As}(\mathrm{III})$ of different samples with satisfactory results.

\section{Experimental}

\section{Instrumentation and reagents}

\section{Instrumentation}

A ZEEnit 700 electrothermal atomic absorption spectrometer (Analytik Jena Instrument Co., Ltd., Germany) equipped with a arsenic hollow cathode lamp, and a Zeeman-based background corrector were used for arsenic determination. The instrumental settings are listed as follows, wavelength: $193.7 \mathrm{~nm}$, spectrum bandwidth: 
$0.8 \mathrm{~nm}$, lamp current: $6.0 \mathrm{~mA}$, matrix modifier: $0.1 \% \mathrm{Pd}\left(\mathrm{NO}_{3}\right)_{2}$. All the absorbance measurements were performed by integrating peak areas. Operating parameters and electrothermal temperature program for arsenic determination were given in Table 1. Fourier transform infrared (FTIR) spectra were recorded by a TENSOR-27 Fourier transform infrared spectrophotometer (Bruker Corporation, Germany). A mode TDL802B centrifuge (Shanghai Anting Science Instrument Factory, Shanghai, China) was used to blend the mixture. $\mathrm{pH}$ measurements were made with a PHS-25B pH meter (Shanghai Precision \& Scientific Instrument Co., Ltd., Shanghai, China) using a combined glass electrode. A digital constant temperature water-bath (Guohua Co., Ltd., China) was used to heat the mixture. Vacuum was achieved by a $2 \mathrm{~K}-82 \mathrm{~B}$ vacuum drying oven (Yichuan, Co., Ltd., China).

Table 1. Instrumental conditions for arsenic species determination

\begin{tabular}{c|c|c|c|c}
\hline Step & $\begin{array}{c}\text { Temperature } \\
\left({ }^{\circ} \mathbf{C}\right)\end{array}$ & $\begin{array}{c}\text { Heating rate } \\
\left({ }^{\circ} \mathbf{C} / \mathbf{S}\right)\end{array}$ & $\begin{array}{c}\text { Hold time } \\
(\mathbf{S})\end{array}$ & $\begin{array}{c}\text { Argon flow rate } \\
(\mathbf{m L} / \mathbf{m i n})\end{array}$ \\
\hline Drying 1 & 90 & 5 & 20 & 250 \\
Drying2 & 110 & 2 & 20 & 250 \\
Pyrolysis & 300 & 250 & 10 & 250 \\
Atomization & 2100 & 3000 & 4 & - \\
Cleaning & 2200 & 500 & 4 & 250 \\
\hline
\end{tabular}

\section{Reagents}

1-Bromohexane, N-methylimidazole, As(III) stock standard solution (1.00 g/L) was prepared by dissolving $0.1320 \mathrm{~g}$ dried $\mathrm{As}_{2} \mathrm{O}_{3}$ in $2.0 \mathrm{~mL}$ of $1.0 \mathrm{mmol} / \mathrm{mL} \mathrm{NaOH}$ solution and adjusting the $\mathrm{pH}$ to 7.0 with $0.5 \mathrm{~mol} / \mathrm{L} \mathrm{HCl}$. As(V) stock standard solution $(1.00 \mathrm{mg} / \mathrm{mL})$ was prepared by sodium arsenate. Working standard solutions were prepared by stepwise diluting the stock solutions just before use. N-Butylimidazole (98\%, Shanghai Darui Fine Chemical Reagent Co., Ltd., Shanghai, China), $\mathrm{KPF}_{6}$ (Aladdin Chemical Reagent Co., Ltd., Los Angeles, USA) and 1-bromobutane were used. Buffer solutions of acetic acid sodium-acetate $(0.2 \mathrm{~mol} / \mathrm{L})$, polyethylene oxide pyridine, glycerol. A certified reference material for arsenic (V) GBW08666 was supplied by Research Center for Eco-Environmental Science, Chinese Academy of Sciences (Beijing, China). All chemicals and reagents used were of analytical reagent grade or higher purity and purchased from Sinopharm Chemical Reagent Co., Ltd. (Shanghai, China) unless otherwise specified. Deionized water used throughout entire work.

River water sample: The river water sample near Yangzhou Thermal Power Plant was collected to study the circulation of inorganic arsenic, the river water sample was filtrated and diluted 10 times prior to detect.

Air sample: For the same reason as above, air sample was collected near Yangzhou Thermal Power Plant. $10 \mathrm{~g}$ polyethylene oxide pyridine was added into $10 \mathrm{~mL}$ glycerol, then mixed with $100 \mathrm{~mL}$ water, neutral filter paper was immersed in the mixture solution for $6 \mathrm{~h}$, then the filter paper was dried under infrared light and packed into a sampler to collect $15.0 \mathrm{~m}^{3}$ gas with the flow rate of $60 \mathrm{~L} / \mathrm{min}$. After the sampling, the filter paper was shredded and put into a $100 \mathrm{~mL}$ beaker. Instead of adding such as nitric acid to digest sample for the determination of total arsenic, only $20 \mathrm{~mL}$ water was added 
to the beaker in this word in order to prevent V(III) from being oxidized to $\mathrm{As}(\mathrm{V})$, then stirring violently for $10 \mathrm{~min}$. The sample solution was filtered with quantitative filter paper, the filtrate was fixed to $100 \mathrm{~mL}$. Finally, $1.0 \mathrm{~mL}$ solution was put it in a $100 \mathrm{ml}$ volume bottle, then set the volume to scale, which was used for the determination of water-soluble inorganic arsenic. It must be pointed out that in the actual sample determination in this experiment the result of air sample determination refers to the concentration of arsenic in the $100 \mathrm{~mL}$ volumetric flask, not the concentration of arsenic in the air.

Soil sample: Soil sample collected was near Yangzhou Thermal Power Plant too. $20 \mathrm{~mL}$ water was added to $0.5 \mathrm{~g}$ soil sample, then the mixture was stirred violently for $10 \mathrm{~min}$. After filter, the filtrate was moved into $100 \mathrm{~mL}$ volumetric flask, the solution was diluted 1000 times prior to detect. Similarly, in the actual sample determination in this experiment, the result of soil sample is that the data was diluted 1000 times, not the concentration of arsenic in the soil sample.

\section{Procedure}

Synthesis of IL (Huddleston et al., 2001)

1-Butyl-3-methylimidazolium chloride was prepared by reaction of equal molar amounts of 1-methylimidazole and chlorobutane in a round-bottomed flask fitted with a reflux condenser by heating and stirring at $70{ }^{\circ} \mathrm{C}$ for $48-72 \mathrm{~h}$. The resulting viscous liquid was allowed to cool to room temperature and then was washed three times with $200 \mathrm{~mL}$ portions of ethyl acetate. The remaining ethyl acetate was removed by heating to $70{ }^{\circ} \mathrm{C}$ under vacuum. To prepare the ionic liquid, hexa-fluorophosphoric acid $(1.3 \mathrm{~mol})$ was added (slowly to prevent the temperature from rising significantly) to a mixture of 1-butyl-3-methylimi-dazolium chloride $(1.0 \mathrm{~mol})$ in $500 \mathrm{~mL}$ of water. After stirring for $12 \mathrm{~h}$, the upper acidic aqueous layer was decanted, the lower ionic liquid portion was washed with water until the washings were no longer acidic. The ionic liquid was then heated under vacuum at $70{ }^{\circ} \mathrm{C}$ to remove excess water. The product was verified by IR spectrum, the results are in agreement with references.

\section{Extraction procedure}

A $0.30 \mathrm{~mL}$ [BMIM] $\left[\mathrm{PF}_{6}\right]$ with $1.0 \mathrm{~mL}$ arsenic sample solution was added into a $5 \mathrm{~mL}$ glass marked centrifuge tube, and added $1.0 \mathrm{~mL}$ acetate/acetic acid buffer, and then diluted to $5 \mathrm{~mL}$ with deionized water. For optimization procedures, $20 \mathrm{ug} / \mathrm{mL}$ $\mathrm{As}(\mathrm{V})$ was used instead of water sample. The tube was first shaken violently, and then the mixture was heated in a water bath for obtaining a dispersion of the ionic liquid into the aqueous media. Finally, the tube was centrifuged at $4000 \mathrm{r} / \mathrm{min}$, then the formation of two well-defined phases was achieved. The aqueous phase were manually removed to analysis the concentration As(III) by ETAAS, and the viscous ionic liquid phase was dissolved in $0.40 \mathrm{~mL}$ of methanol prior to ETAAS measurement.

\section{Results and discussion}

In the research, the optimization method of single factor experiment design is first used to optimize the experimental conditions, and on the basis of the optimization conditions of the single factor experiment method, the cross-effect of each factor is 
considered comprehensively. Then, the experimental conditions was optimized by orthogonal experiment design.

\section{Optimization of experimental parameters by single factor optimization method}

\section{Effect of $p H$}

The effect of $\mathrm{pH}$ on the extraction efficiency of $\mathrm{As}(\mathrm{V})$ and $\mathrm{As}(\mathrm{III})$ was investigated separately over the $\mathrm{pH}$ range of 4.0-11.0. The results presented in Figure 1 indicate that the quantitative recovery $(>92.0 \%)$ of $\mathrm{As}(\mathrm{V})$ was achieved at a $\mathrm{pH}$ range of 4.0 to 7.0, while the extraction rate of As(III) was less than 7.0\%. The reason for the selective extraction of $\mathrm{As}(\mathrm{V})$ maybe explained that $\mathrm{As}(\mathrm{V})$ was associated with positive ion of $[\mathrm{BMIM}]\left[\mathrm{PF}_{6}\right]$ by electrostatic interaction to form a hydrophobic complex compound, leading to the quantitative recovery of $\mathrm{As}(\mathrm{V})$.

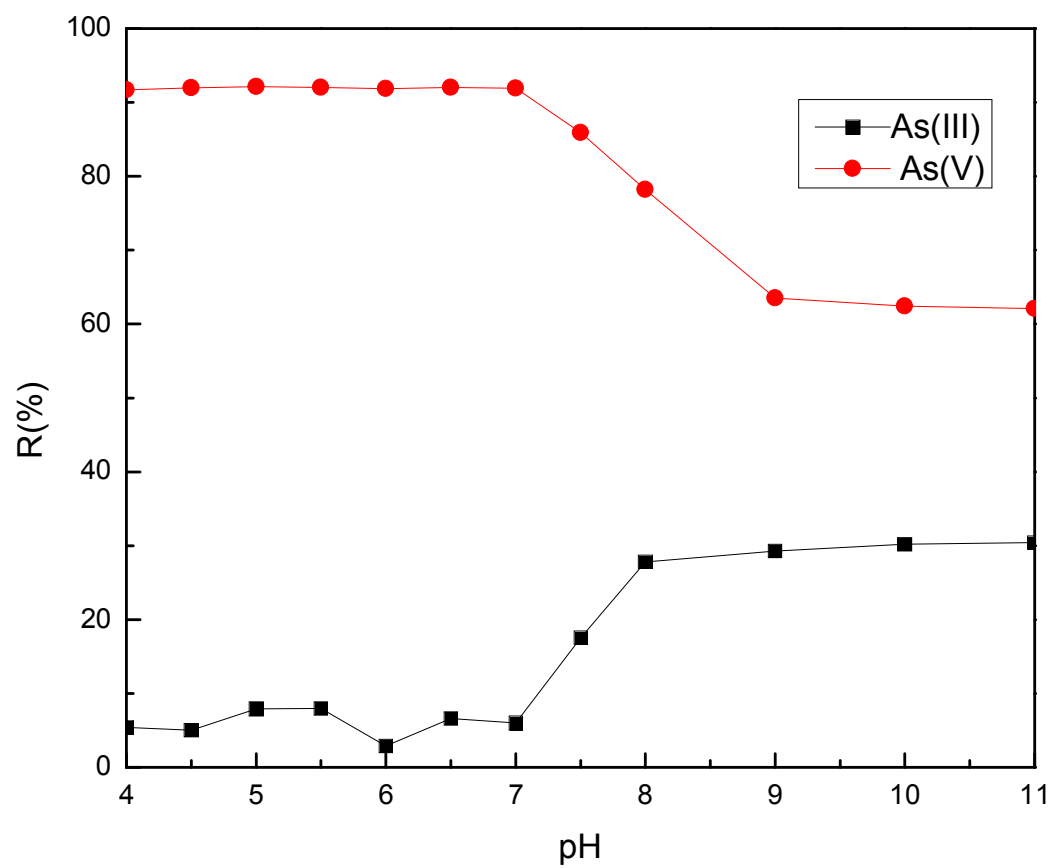

Figure 1. Effect of $p H$

$\mathrm{As}(\mathrm{V})$ and $\mathrm{As}(\mathrm{III})$ exist in both molecular and ionic forms depending on the $\mathrm{pH}$ value of the solution. The stability and speciation of inorganic arsenic compounds depend on $\mathrm{pH}$ of solution, as presented in Figure 2 (Sullivan et al., 2010). In the range of $\mathrm{pH} 4.0$ 7.0, $\mathrm{As}(\mathrm{V})$ mainly exists as $\mathrm{H}_{2} \mathrm{AsO}_{4}^{-}$, which can be easily reacted with positive ion of $[\mathrm{BMIM}]\left[\mathrm{PF}_{6}\right]$ to form a stable compound:

$$
\mathrm{C}_{6} \mathrm{H}_{11} \mathrm{~N}_{2}{ }^{+} \cdot \mathrm{PF}_{6}^{-}+\mathrm{H}_{2} \mathrm{As}_{5} \mathrm{O}_{4}^{-} \rightarrow \mathrm{C}_{6} \mathrm{H}_{11} \mathrm{~N}_{2}^{+} \cdot \mathrm{H}_{2} \mathrm{AsO}_{4}{ }^{-}+\mathrm{PF}_{6}^{-}
$$

Therefore, the higher recovery rate of $\mathrm{As}(\mathrm{V})$ was obtained when $\mathrm{pH} \leq 7.0$.

However, $\mathrm{As}(\mathrm{III})$ tends to be as a neutral molecule $\left(\mathrm{H}_{3} \mathrm{AsO}_{3}\right)$ when $\mathrm{pH} \leq 7.0$, it can not combine with the cation of [BMIM] $\left[\mathrm{PF}_{6}\right]$, decreasing the recovery of As(III).

In order to selectively determine $\mathrm{As}(\mathrm{V})$ and avoid the interference of $\mathrm{As}(\mathrm{III})$, the $\mathrm{pH}$ 6.0 was chosen in the rest of the work. 

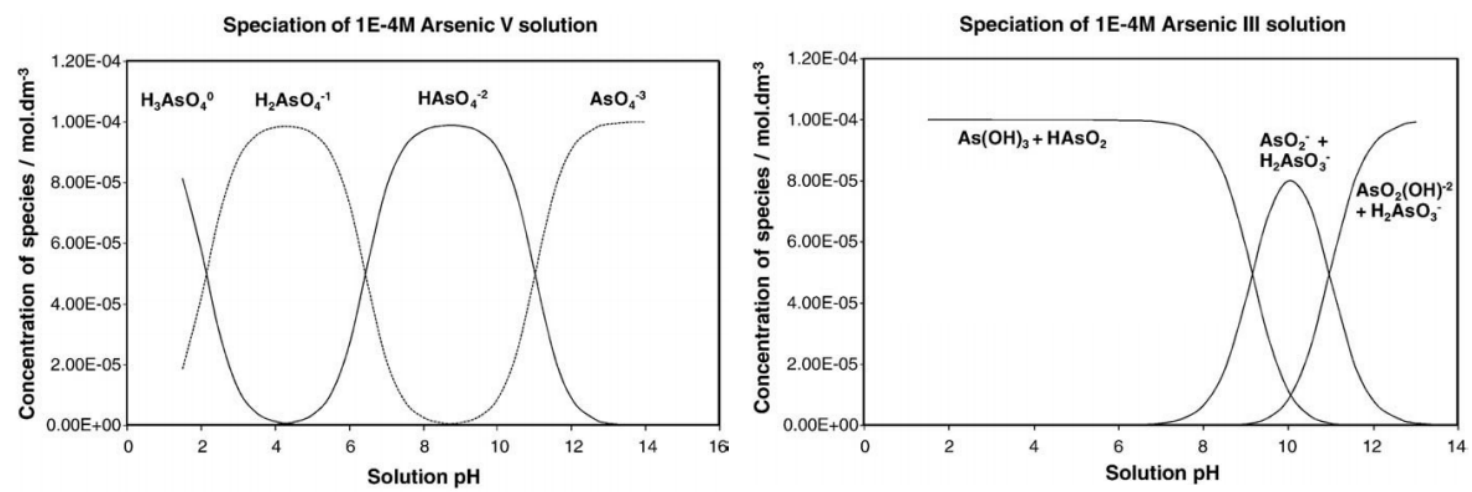

Figure 2. Stability and speciation of arsenic compounds

\section{Effect of volume of [BMIM]PF $]$}

Different volumes of [BMIM] $\left.\mathrm{PF}_{6}\right]$ were investigated, and the results were shown in Figure 3. For $\mathrm{As}(\mathrm{V})$, the recovery rate increased with the increase of [BMIM] $\left.\mathrm{PF}_{6}\right]$ amount from $0.1 \mathrm{~mL}$ to $0.3 \mathrm{~mL}$, and the maximum recovery was obtained when the volume of [BMIM]PF 6 was $0.3 \mathrm{~mL}$, whereas the recovery of As(III) was less than $7 \%$.

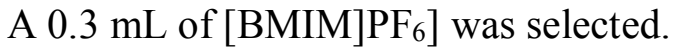

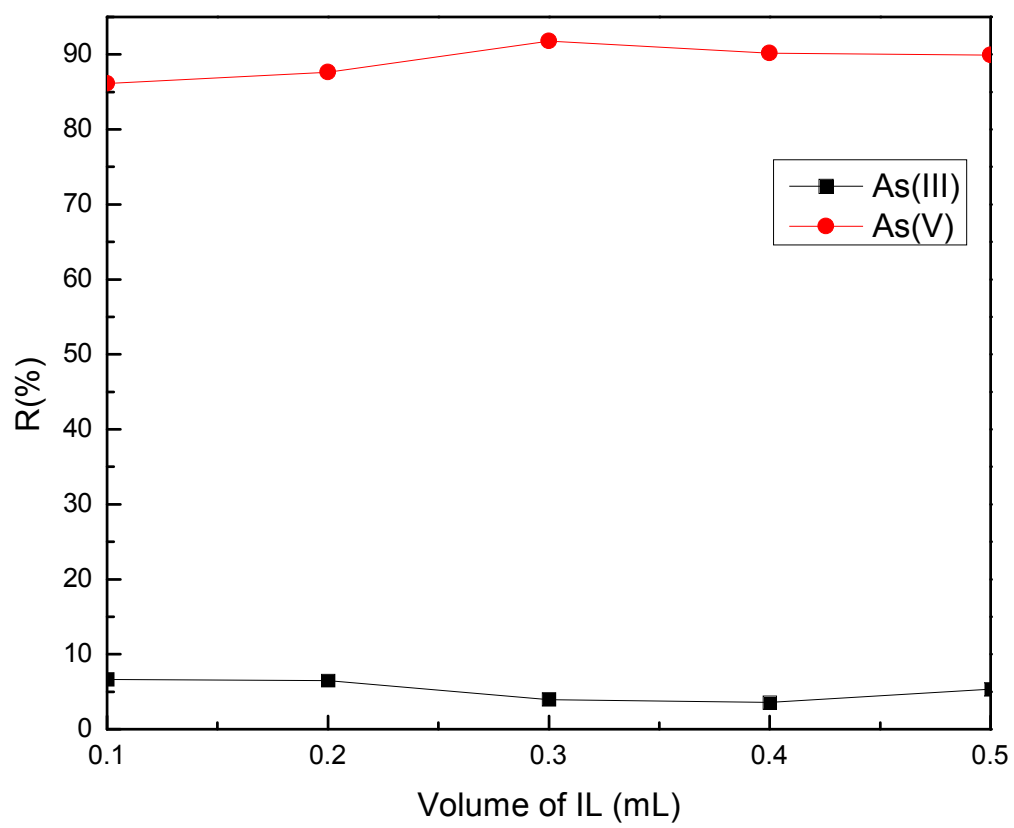

Figure 3. Effect of the volume of [BMIM]PF $]$

\section{Effect of salt}

The effect of salt was investigated with $\mathrm{NaCl}$ concentration ranging from 0 to $15 \%$ $(\mathrm{W} / \mathrm{V})$. As shown in Figure 4, the recovery ratio of $\mathrm{As}(\mathrm{V})$ decreased tardily with the addition of salts concentration, for the solubility of $\mathrm{As}(\mathrm{V})$ was increased with salts addition, as a result, the extraction ration decreased lightly when salts was added. Thus, salt addition was not adopted for further experiments. 


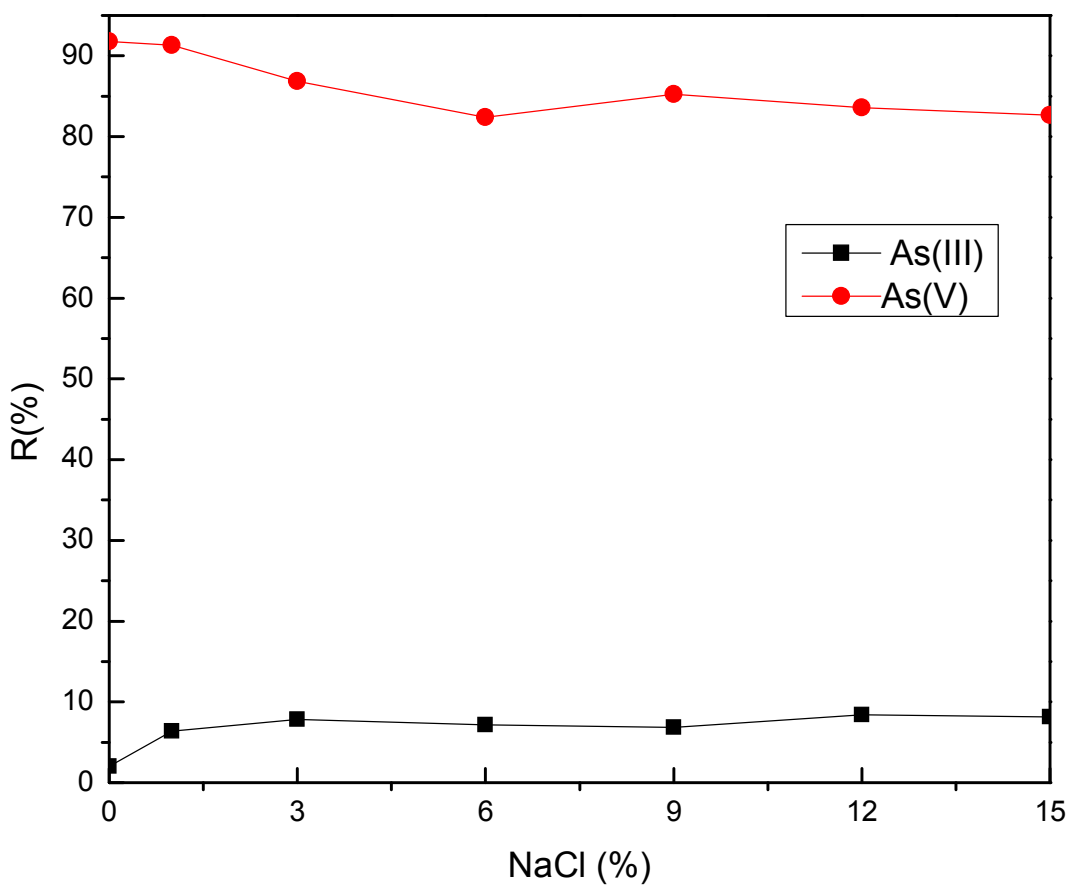

Figure 4. Effect of salt

\section{Effect of extraction temperature}

The effect of extraction temperature was examined in the range of $15-65^{\circ} \mathrm{C}$, as shown in Figure 5. Recovery ratio of $\mathrm{As}(\mathrm{V})$ was maximum at $45^{\circ} \mathrm{C}$; so $45^{\circ} \mathrm{C}$ was selected.

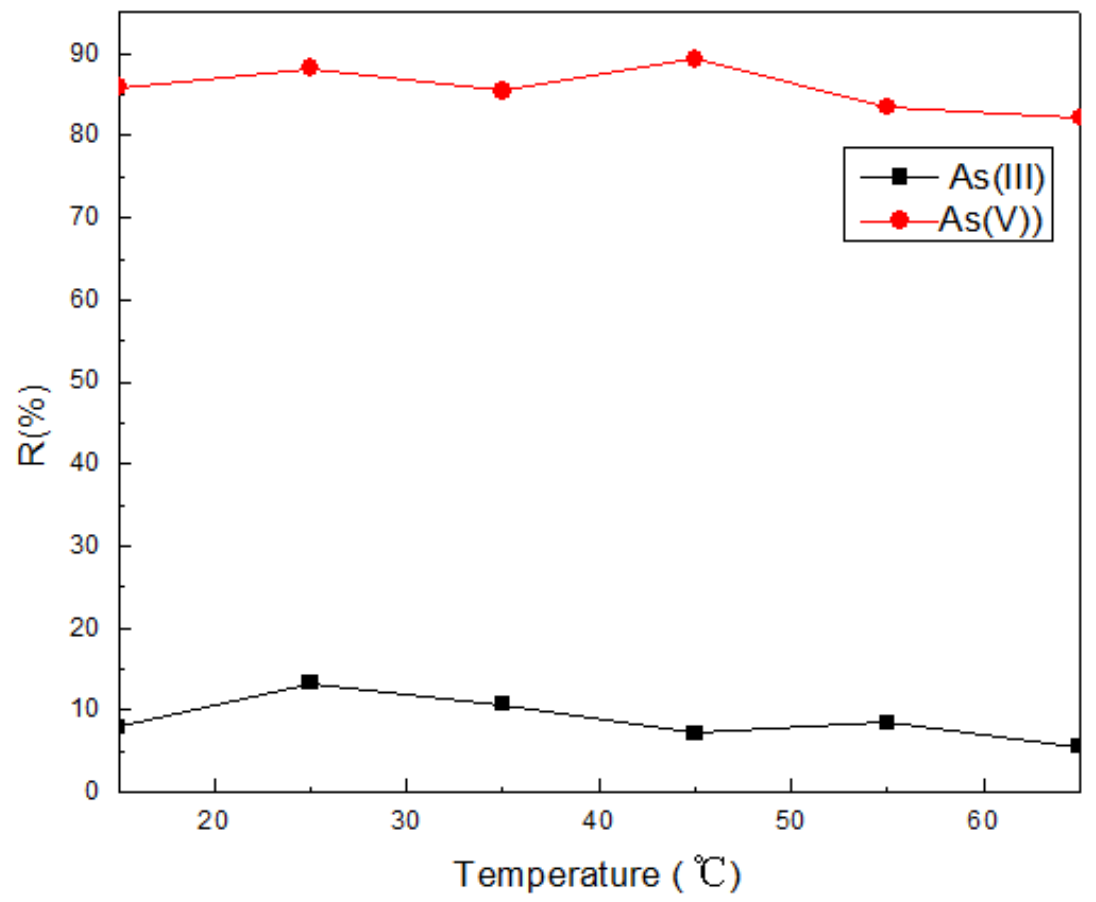

Figure 5. Effect of temperature 


\section{Effect of extraction time}

The influence of extraction time was investigated in the range from 5 to $30 \mathrm{~min}$. Figure 6 shows that 20 min was sufficient for the quantitative extraction $(90 \%)$ of $\mathrm{As}(\mathrm{V})$, while the extraction efficiency of As(III) was very low (below 10\%) in the tested time range. Thus, the extraction time of 20 min was used.

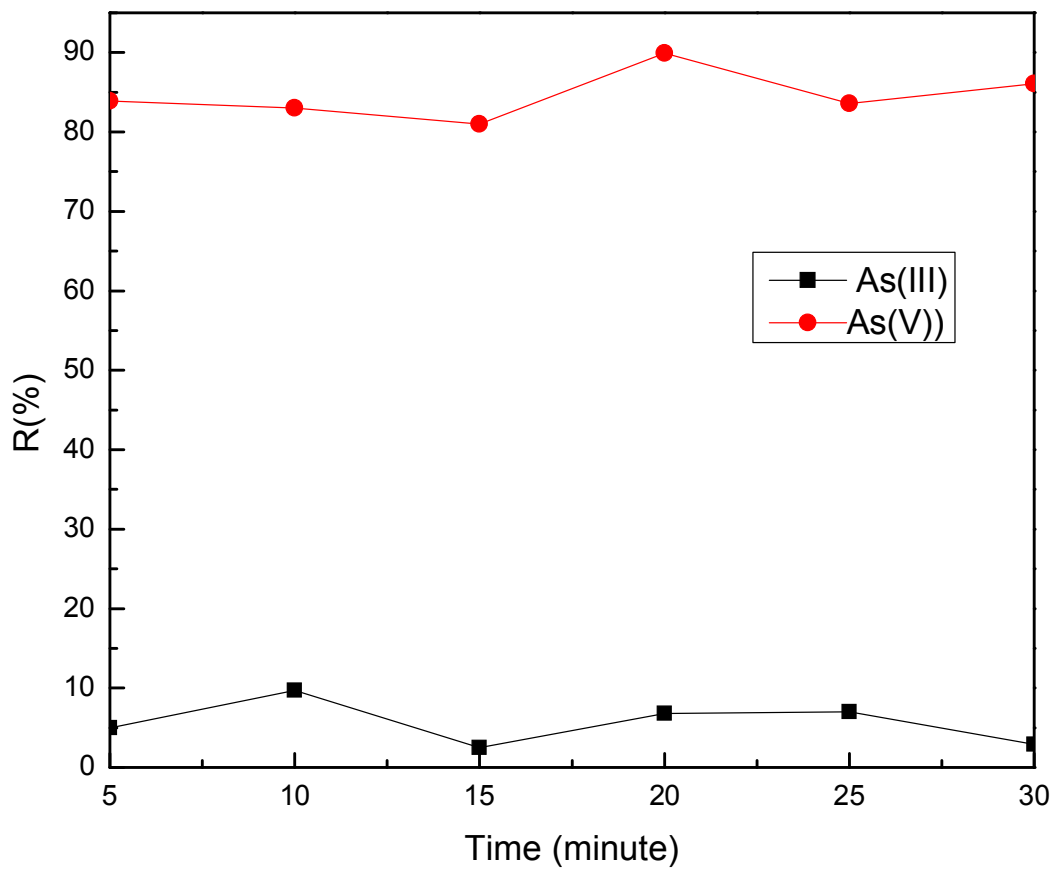

Figure 6. Effect of the time of extraction

\section{Optimization of adsorption parameters by orthogonal experiment design}

It is simple to use the single factor experiment method when optimizing the experimental conditions, but it must be assumed that the method can only be used when there is no interference between factors. If there is a cross-effect between factors, the use of this method may lead to a wrong result. In fact, factors are less independent of each other. Therefore, on the basis of single factor experiment, the orthogonal design is used to optimize the extraction conditions in this study. For there is little effect of salt on the extraction process, the effect of salt is not taken into account in orthogonal design. Above and below the optimum experimental conditions obtained by single factor experiment method, the orthogonal experiment design is used to optimize the experimental parameters, details are shown in the Table 2.

As can be seen from Table 2, the importance of the factors that affect the extraction rate of $\mathrm{As}(\mathrm{V})$ is significantly different, the order of factors is (from large to small): $\mathrm{pH}>$ volume of $[\mathrm{BMIM}] \mathrm{PF}_{6}>$ extraction temperature $>$ extraction time. For As(III), there is little difference in the range of factors affecting the extraction. In pursuit of an increase in the extraction rate of $\mathrm{As}(\mathrm{V})$, the selected experimental conditions are as follows, $\mathrm{pH}: 6.5$, volume of [BMIM] $\mathrm{PF}_{6}: 0.5 \mathrm{~mL}$, extraction temperature is $35^{\circ} \mathrm{C}$, and extraction time is $20 \mathrm{~min}$, under this condition, the extraction rate of $\mathrm{As}(\mathrm{V})$ is more than $92 \%$ with the extraction rate of $\mathrm{As}(\mathrm{III})$ is less than $7 \%$. 
Table 2. Optimization of parameters by orthogonal experiment design

\begin{tabular}{|c|c|c|c|c|c|c|c|}
\hline \multirow{2}{*}{\multicolumn{2}{|c|}{ Level }} & \multirow{2}{*}{$\mathbf{p H}$} & \multirow{2}{*}{$\mathbf{V}(\mathbf{m L})$} & \multirow{2}{*}{ Et $\left({ }^{\circ} \mathrm{C}\right)$} & \multirow{2}{*}{$T(\min )$} & \multicolumn{2}{|c|}{$\operatorname{Er}(\%)$} \\
\hline & & & & & & $\mathbf{A s}(\mathrm{III})$ & $\operatorname{As}(\mathrm{V})$ \\
\hline \multicolumn{2}{|c|}{1} & 6.0 & 0.2 & 35 & 10 & 2.0 & 81.4 \\
\hline \multicolumn{2}{|c|}{2} & 6.0 & 0.3 & 45 & 15 & 4.5 & 88.5 \\
\hline \multicolumn{2}{|c|}{3} & 6.0 & 0.4 & 55 & 20 & 8.2 & 85.7 \\
\hline \multicolumn{2}{|c|}{4} & 6.0 & 0.5 & 65 & 25 & 8.8 & 83.2 \\
\hline \multicolumn{2}{|c|}{5} & 6.5 & 0.2 & 45 & 20 & 7.7 & 86.9 \\
\hline \multicolumn{2}{|c|}{6} & 6.5 & 0.3 & 35 & 25 & 7.1 & 87.8 \\
\hline \multicolumn{2}{|c|}{7} & 6.5 & 0.4 & 65 & 10 & 8.1 & 84.1 \\
\hline \multicolumn{2}{|c|}{8} & 6.5 & 0.5 & 55 & 15 & 8.5 & 84.9 \\
\hline \multicolumn{2}{|c|}{9} & 7.0 & 0.2 & 55 & 25 & 8.9 & 83.2 \\
\hline \multicolumn{2}{|c|}{10} & 7.0 & 0.3 & 65 & 20 & 6.7 & 87.4 \\
\hline \multicolumn{2}{|c|}{11} & 7.0 & 0.4 & 35 & 15 & 12.2 & 88.3 \\
\hline \multicolumn{2}{|c|}{12} & 7.0 & 0.5 & 45 & 10 & 6.9 & 85.1 \\
\hline \multicolumn{2}{|c|}{13} & 7.5 & 0.2 & 65 & 15 & 7.2 & 68.7 \\
\hline \multicolumn{2}{|c|}{14} & 7.5 & 0.3 & 55 & 10 & 9.2 & 70.4 \\
\hline \multicolumn{2}{|c|}{15} & 7.5 & 0.4 & 45 & 25 & 7.0 & 72.5 \\
\hline \multicolumn{2}{|c|}{16} & 7.5 & 0.5 & 35 & 20 & 6.7 & 76.8 \\
\hline \multirow{5}{*}{ As (V) } & $\mathrm{K} 1$ & 85.575 & 77.275 & 84.1 & 80.85 & & \\
\hline & $\mathrm{K} 2$ & 85.95 & 83.4 & 83.4 & 82.15 & & \\
\hline & $\mathrm{K} 3$ & 85.725 & 84.375 & 81.3 & 83.425 & & \\
\hline & K4 & 72.4 & 84.6 & 80.85 & 83.225 & & \\
\hline & Range & 13.55 & 7.325 & 3.25 & 2.575 & & \\
\hline \multirow{5}{*}{ As (III) } & K1 & 5.875 & 6.45 & 7 & 6.55 & & \\
\hline & K2 & 7.85 & 6.875 & 6.525 & 8.1 & & \\
\hline & $\mathrm{K} 3$ & 8.675 & 8.875 & 8.7 & 7.325 & & \\
\hline & K4 & 7.525 & 7.725 & 7.7 & 7.95 & & \\
\hline & Range & 2.8 & 2.425 & 2.175 & 1.55 & & \\
\hline
\end{tabular}

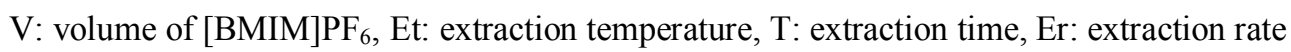

\section{Interference}

\section{Interference of As(III)}

The interference between $\mathrm{As}(\mathrm{III})$ and $\mathrm{As}(\mathrm{V})$ was evaluated. The results showed that no remarkable influences were observed on the determination of $\mathrm{As}(\mathrm{V}) / \mathrm{As}(\mathrm{III})$ at the concentration ratio of $\mathrm{As}(\mathrm{III})$ to $\mathrm{As}(\mathrm{V})$ within 20 -fold, the good recoveries have been obtained and the two species can be separated.

\section{Interference of other metal ions}

To evaluate the potential interference of other metal ions, different foreign metal ions were added individually to a series of standard working solution containing $20.00 \mathrm{ng} / \mathrm{mLAs}(\mathrm{V}) / \mathrm{As}(\mathrm{III})$. A variation on the recovery higher than $\pm 5 \%$ was considered as interference. The tolerance limits (metal ion/As, w/w) of foreign ions on the determination of $\mathrm{As}(\mathrm{III}) / \mathrm{As}(\mathrm{V})$ were summarized as in Table 3. 
Table 3. Effect of interfering ions of As

\begin{tabular}{c|c}
\hline Interferences ions & Tolerance ratio (w/w) \\
\hline $\mathrm{Pb}^{2+}, \mathrm{Sn}(\mathrm{IV}), \mathrm{Zn}^{2+}, \mathrm{Cd}^{2+}$ & 10 \\
$\mathrm{Fe}^{3+}, \mathrm{Mg}^{2+}, \mathrm{Ca}^{2+}, \mathrm{Cr}(\mathrm{VI}), \mathrm{Cl}^{-}, \mathrm{F}^{-}, \mathrm{HCO}_{3}{ }^{-}$ & 100 \\
$\mathrm{~K}^{+}, \mathrm{Na}^{+}, \mathrm{Cu}^{2+}, \mathrm{Ni}^{2+}, \mathrm{SO}_{4}{ }^{2-}, \mathrm{NH}_{4}{ }^{+}$ & 200 \\
\hline
\end{tabular}

\section{Performance of the method}

The proposed method was evaluated under the optimum conditions described above. According to the International Union of Pure and Applied Chemistry definition, the detection limits $(3 \sigma)$ of this method was $0.04 \mathrm{ng} / \mathrm{mL}$ for $\mathrm{As}(\mathrm{V})$ and $0.53 \mathrm{ng} / \mathrm{mL}$ for As(III). The relative standard deviations for six replicates extractions at $20.00 \mathrm{ng} / \mathrm{mL}$ level of $\mathrm{As}(\mathrm{V})$ was $3.5 \%$, and As(III) was $2.9 \%$. The preconcentration factor was 12.5 fold for $\mathrm{As}(\mathrm{V})$, which was calculated as the volume ratio of the sample solution $(5.00 \mathrm{~mL})$ to the $[\mathrm{BMIM}]\left[\mathrm{PF}_{6}\right]$ phase after the dilution with methanol $(0.40 \mathrm{~mL})$.

\section{Comparison of the present method with others}

Comparing the analytical features of the method with other studies (Table 4), the results demonstrates that this method is superior in terms of LOD of As(V). It should be noted in particular that no chelating reagent has been added to this method and no organic reagent has been used in the whole extraction process. Compared with other methods, this is less harmful to the environment, greener, more economical, and more environmentally friendly.

Table 4. Comparison of analytical features of proposed method with other methods

\begin{tabular}{c|c|c|c|c|c}
\hline \multirow{2}{*}{ Method } & \multicolumn{2}{|c|}{ LOD (ug.L - $^{-1}$ ) } & \multicolumn{2}{c|}{ Calibration range(ug.L-1) } & \multirow{2}{*}{ Reference } \\
\cline { 2 - 5 } & $\mathbf{A s}(\mathbf{V})$ & $\mathbf{A s}(\mathrm{III})$ & $\mathbf{A s}(\mathbf{V})$ & $\mathbf{A s}(\mathrm{III})$ & \\
\hline ASCP & 0.55 & 0.42 & $0.5-200$ & $0.5-200$ & Jedryczko et al.(2016) \\
HPLC-HG-ICP-MS & 0.3 & 0.1 & $1-750$ & $1-300$ & Gomez-Ariza et al. (2000) \\
LC-HG-AFS & 1.5 & 0.5 & $>800$ & $>800$ & Vilanó et al. (2000) \\
FI-HG-AFS & 0.05 & - & $0.1-3.0$ & - & Leal et al. (2006) \\
PCL & 0.44 & 0.27 & $0-50$ & $0-50$ & Sengupta et al. (2010) \\
SPE-ETAAS & 20 & 28 & - & - & Arain et al. (2016) \\
IL-LLME-ETAAS & 0.04 & 0.35 & $0.47-72.0$ & $1.02-75.3$ & This paper \\
\hline
\end{tabular}

LOD: limits of detection

\section{Method application}

To validate the accuracy and precision of the proposed method, arsenic species were analyzed in a certified reference material for GBW08666. The results in Table 3 shows that almost no As(III) was detected in the reference GBW08666, and the content of $\mathrm{As}(\mathrm{V})$ was in good agreement with the certified value of $14.39 \mathrm{ng} / \mathrm{mL}$. Furthermore, the recovery results for $\mathrm{As}(\mathrm{V}) / \mathrm{As}(\mathrm{III})$ in the reference were in the range of $93.4-104.4 \%$. That could be concluded that the method was feasible and accurate for the determination of $\mathrm{As}(\mathrm{V}) / \mathrm{As}(\mathrm{III})$ species. 
The method was also applied to the determination of $\mathrm{As}(\mathrm{V}) / \mathrm{As}(\mathrm{III})$ in three kinds of samples. The results and the recovery for the spiked samples are given in Table 5. The $\mathrm{As}(\mathrm{V})$ extraction rate of standard addition is between $96.5 \%$ and $106.4 \%$ in the detection of various practical sample, while As(III) is between $97.2 \%$ and $106.8 \%$.

Table 5. Determination of $A s(I I I)$ and $A s(V)$ in real samples and certified reference material

\begin{tabular}{c|c|c|c|c|c|c|c|c}
\hline \multirow{2}{*}{ Sample } & \multicolumn{2}{|c|}{ Added (ng/mL) } & \multicolumn{3}{c|}{ Found (ng/mL) } & \multicolumn{3}{c}{ Recovery (\%) } \\
\cline { 2 - 9 } & $\mathbf{A s}(\mathrm{III})$ & $\mathbf{A s}(\mathbf{V})$ & $\mathbf{A s}(\mathrm{III})$ & $\mathbf{A s}(\mathbf{V})$ & Total As & As(III) & As(V) & Total As \\
\hline \multirow{3}{*}{ GBW08666* } & 0 & 0 & ND & 14.84 & 14.84 & - & 103.1 & 103.1 \\
& 14.76 & 12.87 & 13.78 & 27.52 & 41.30 & 93.4 & 102.0 & 98.3 \\
& 29.52 & 25.74 & 27.83 & 41.27 & 69.10 & 94.3 & 104.4 & 99.2 \\
\hline \multirow{3}{*}{ Air sample } & 0 & 0 & 0.75 & 1.22 & 1.97 & - & - & - \\
& 5.0 & 5.0 & 5.61 & 6.42 & 12.03 & 97.2 & 104.0 & 100.6 \\
& 10.0 & 10.0 & 10.59 & 10.87 & 21.46 & 98.4 & 96.5 & 97.5 \\
\hline \multirow{4}{*}{ River water } & 0 & 0 & 1.23 & 2.15 & 3.38 & - & - & - \\
& 5.0 & 5.0 & 6.07 & 7.23 & 13.32 & 96.8 & 101.3 & 99.4 \\
& 10.0 & 10.0 & 11.33 & 12.49 & 23.82 & 101.0 & 106.4 & 102.2 \\
\hline \multirow{3}{*}{ Soil sample } & 0 & 0 & 4.34 & 10.42 & 14.76 & - & - & - \\
& 5.0 & 5.0 & 9.68 & 15.25 & 24.93 & 106.8 & 96.6 & 101.7 \\
& 10.0 & 10.0 & 14.57 & 20.83 & 35.40 & 102.3 & 104.1 & 103.2 \\
\hline
\end{tabular}

*Standard samples $\left(\mathrm{C}_{\mathrm{As}(\mathrm{V})}=14.39 \mathrm{ng} / \mathrm{mL}\right)$ was diluted appropriately before determination

ND: not founded

\section{Conclusion}

In this paper, hydrophobic ionic liquid 1-butyl-3-methylimidazolium hexafluorophosphate was synthesized to extract and separate iAs species, The experimental conditions were optimized by single factor experiment and orthogonal design method. The whole process was carried out without any chelating/dispersive agent. The method sees to be simple, sensitive, and efficient. With the proposed procedures, satisfactory results of iAs species in different samples were obtained. The proposed method is recommended for iAs determinations in environmental samples.

Acknowledgements. The authors acknowledge the financial support from the National Natural Science Foundation of China (21375117), a project funded by the Priority Academic Program Development of Jiangsu Higher Education Institutions, and a funded by Yangzhou environmental protection bureau.

\section{REFERENCES}

[1] Abdolmohammad-Zadeh, H., Jouyban, A., Amini, R. (2013): Ultratrace determination of arsenic in water samples by electrothermal atomic absorption spectrometry after preconcentration with $\mathrm{Mg}$-Al-Fe ternary layered double hydroxide nano-sorbent. - Talanta 116(22): 604-610.

[2] Arain, S. A., Kazi, T. G., Afridi, H. I., Arain, M. S., Panhwar, A. H., Khan. N., Baig, J. A., Shah, F. (2016): A new dispersive liquid-liquid microextraction using ionic liquid based microemulsion coupled with cloud point extraction for determination of copper in serum and water samples. - Ecotoxicology Environmental Safety 126: 186-192. 
[3] Gomez-Ariza, J. L., Sanchez-Rodas, D., Giraldez, I., Morales, E. (2000): A comparison between ICP-MS and AFS detection for arsenic speciation in environmental samples Talanta 51(2): 257-268.

[4] Huddleston, J. G., Visser, A. E., Reichert, W. M., Willauer, H. D., Broker, G. A., Rogers, R. D. (2001): Characterization and comparison of hydrophilic and hydrophobic room temperature ionic liquids incorporating the imidazoliumcation cation. - Green Chemistry 3(4): 156-164.

[5] Jedryczko, D., Pohl, P., Welna, M. (2016): Inorganic arsenic speciation in natural mineral drinking waters by flow-through anodic stripping chronopotentiometry. - Talanta 150 : 265-271.

[6] Leal, L. O., Forteza, R., Cerdà, V. (2006): Speciation analysis of inorganic arsenic by a multisyringe flow injection system with hydride generation-atomic fluorescence spectrometric detection. - Talanta 69(2): 500-508.

[7] Li, J., Sun, C., Zheng, L., Jiang, F., Wang, S., Zhuang, Z., Wang, X. (2017): Determination of trace metals and analysis of arsenic species in tropical marine fishes from Spratly islands. - Marine Pollution Bulletin 122(1-2): 464-469.

[8] Ministry of Public Health of the People's Republic of China (2007): Occupational exposure limits for hazardous agents in the workplace. - Dissertation.

[9] Nellaiappan, S., Pillai, K. C., Kumar, A. S. (2018): Flow-injection analysis coupled electrochemical detection of poisonous inorganic arsenic(III) species using a gold nanoparticle/carbon nanofiber/chitosan chemically modified carbon screen printed electrode in neutral $\mathrm{pH}$ solution. - Analytical Methods 10(7)799-808.

[10] Pourghazi, K., Amoli-Diva, M., Beiraghi, A. (2015): Speciation of ultra-trace amounts of inorganic arsenic in water and rice samples by electrothermal atomic absorption spectrometry after solid-phase extraction with modified $\mathrm{Fe} 3 \mathrm{O} 4$ nanoparticles. International Journal of Environmental Analytical Chemistry 95(4): 15.

[11] Sha, O., Zhu, X. S. (2014): Determination of gold(III) by simplified room-temperature ionic liquid extraction with flame atomic absorption spectrometry. - Analytical Letters 47(6): 1052-1062.

[12] Sengupta, M. K., Hossain, Z. A., Ohira, S. I., Dasgupta, P. K. (2010): A simple inexpensive gas phase chemiluminescence analyzer for measuring trace levels of arsenic in drinking water. - Environmental Pollution 158(1): 252-257.

[13] Squibb, K. S., Fowler, B. A. (1983): The Toxicity of Arsenic and Its Compounds. Elsevier Science, New York.

[14] Stanisz, E., Werner, J., Zgoła-Grześkowiak, A. (2014): Liquid-phase microextraction techniques based on ionic liquids for preconcentration and determination of metals. TrAC Trends in Analytical Chemistry 61: 54-66.

[15] Sullivan, C., Tyrer, M., Cheeseman, C. R., Graham, N. J. D. (2010) Disposal of water treatment wastes containing arsenic - a review. - Science of the Total Environment 408: 1770-1778.

[16] Tunçeli, A., Ocak, G., Acar, O., Türker, A. R. (2015): Development of a method for speciation of inorganic arsenic in waters using solid phase extraction and electrothermal atomic absorption spectrometry. - International Journal of Environmental Analytical Chemistry 95(14): 1-17.

[17] United States Environmental Protection Agency (2002): Implementation Guidance for the Arsenic Rule. Drinking Water Regulations for Arsenic and Clarifications to Compliance and New Source Contaminants Monitoring Guidance. - EPA, Washington, DC.

[18] Vilanó, M., Padró, A., Rubio, R. (2000): Coupled techniques based on liquid chromatography and atomic fluorescence detection for arsenic speciation. - Analytical Chimica Acta 411(1-2): 71-79.

[19] Wang, X, Xu, G., Chen, P., Sun, Y. S., Yao, X.T., Lv, Y., Guo, W. W., Wang, G. Z. (2018): Fully-automated magnetic stirring-assisted lab-in-syringe dispersive liquid-liquid 
microextraction for the determination of arsenic species in rice samples. - RSC Advances 8(30): 16858-16865.

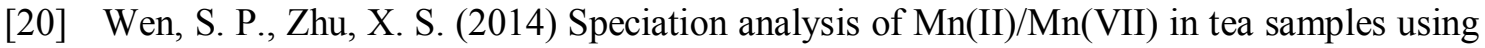
flame atomic absorption spectrometry after room temperature ionic liquid-based dispersive liquid-liquid microextraction. - Food Analytical Methods 7(2): 291-297.

[21] Wen, S. P., Wu, J., Zhu, X. S. (2013): Room temperature ionic liquid-based dispersive liquid-liquid microextraction combined with flame atomic absorption spectrometry for the speciation of chromium(III) and chromium(VI). - Journal of Molecular Liquids 180(4): 59-64.

[22] Wen, S. P., Zhu, X. S., Wu, X. Y., Qin, X. X. (2014): Directly suspended droplet microextractioncoupled with electrothermal atomic absorption spectrometry for the speciation of chromium(III)/chromium(VI). - Analytical Methods 6(24): 9777-9782. 